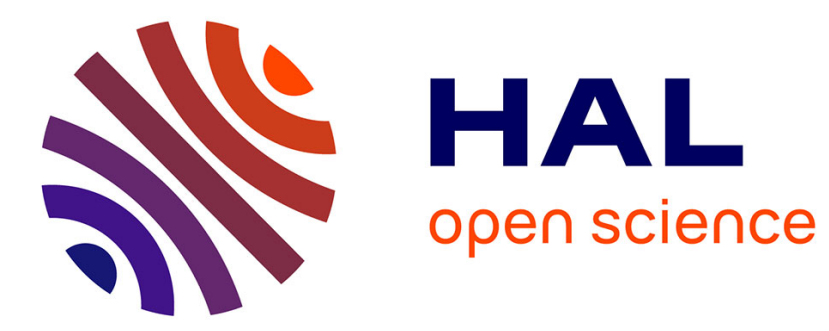

\title{
Site selective spectroscopy and RBS/channeling in optically active ion doped LiNbO3 crystals
}

\author{
J. Garcia Sole, A. Lorenzo, Thomas Petit, G. Boulon, B. Roux, H. Jaffrezic
}

\section{To cite this version:}

J. Garcia Sole, A. Lorenzo, Thomas Petit, G. Boulon, B. Roux, et al.. Site selective spectroscopy and RBS/channeling in optically active ion doped LiNbO3 crystals. Journal de Physique IV Proceedings, 1994, 04 (C4), pp.C4-293-C4-296. 10.1051/jp4:1994472 . jpa-00252735

\section{HAL Id: jpa-00252735 https://hal.science/jpa-00252735}

Submitted on 1 Jan 1994

HAL is a multi-disciplinary open access archive for the deposit and dissemination of scientific research documents, whether they are published or not. The documents may come from teaching and research institutions in France or abroad, or from public or private research centers.
L'archive ouverte pluridisciplinaire HAL, est destinée au dépôt et à la diffusion de documents scientifiques de niveau recherche, publiés ou non, émanant des établissements d'enseignement et de recherche français ou étrangers, des laboratoires publics ou privés. 


\title{
Site selective spectroscopy and RBS/channeling in optically active ion doped $\mathrm{LiNbO}_{3}$ crystals
}

\author{
J. GARCIA SOLE*,(1), A. LORENZO*,(1), T. PETIT* , G. BOULON* ${ }^{*}$, B. ROUX ${ }^{* *}$ and \\ H. JAFFREZIC ${ }^{* *}$
}

* Laboratoire de Physico-Chimie des Matériaux Luminescents, Université Claude Bernard Lyon I, Bât. 205, 69622 Villeurbanne cedex, France

** Groupe Traitements de Surfaces, Institut de Physique Nucléaire, Université Claude Bernard Lyon I, 69622 Villeurbanne cedex, France

\section{INTRODUCTION}

$\mathrm{LiNbO}_{3}$ is a non-linear crystal with a variety of possible applications as a host laser matrix. Doping with laser active centers can lead to small compact lasers (minilasers) including several functions (self-frequency doubling, self-Q switching, waveguides ...) required in integrated optics [1]. The presence of non-equivalent centres (multicentres) has been recently ascertained for a number of ion-doped $\mathrm{LiNbO}_{3}$ systems [2]. However, the structure and lattice location of these multicentres are still being subject of controversy.

According to that, several optically active ion-doped $\mathrm{LiNbO}_{3}$ crystals have been investigated by using, in parallel, two quite different techniques. By site selective spectroscopy (SSS) we can determine the number of non-equivalent multicentres as well as their spectroscopic properties. By Rutherford backscattering spectrometry (RBS)/channeling the lattice site(s) occupied by the dopant ions can be determined [3].

Combining these two techniques on the same crystals we have studied the $\mathrm{Nd}^{3+}, \mathrm{Pr}^{3+}$ and $\mathrm{Yb}^{3+}$ multicentres and their lattice location in the $\mathrm{LiNbO}_{3}$ host.

\section{EXPERIMENTAL}

Congruent $\mathrm{LiNbO}_{3}$ crystals doped either with $(0.2 \%, 0.5 \%) \operatorname{Pr},(1 \%) \mathrm{Nd}$ or ( $0.5 \%) \mathrm{Yb}$ were grown by the Czochralski technique. SSS was performed exciting either with a Ti-Sapphire laser or with a $\mathrm{N}_{2}$ pumped pulsed dye laser. RBS/Channeling experiments with $\mathrm{He}^{+}$ions were carried out in a $2 \mathrm{MV}$ Van de Graaff accelerator of the Institut de Physique de Lyon. The same samples were used in the SSS and RBS experiments, so that possible Spain

(1) On leave from Departamento de Fisica de Materiales, C-IV. Universidad Autonoma de Madrid, 28049 Madrid, 
variations from crystal to crystal were discarded.

RESULTS

Figure 1 shows the $15 \mathrm{~K}$ optical spectra (absorption-Pr and $\mathrm{Yb}$ - or excitation-Nd-) corresponding to single transitions between defined Stark

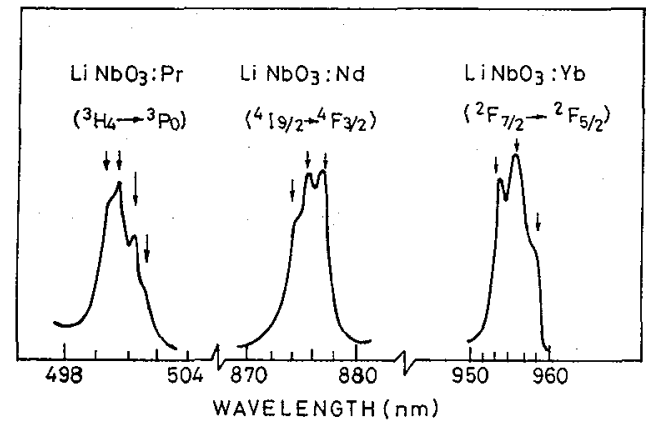

Figure 1

levels (states indicated in the figure) for the three ions investigated in this work. Thus the structure appearing in these bands indicates the presence of, at least, three non-equivalent centres for the $\mathrm{Nd}^{3+}$ and $\mathrm{Yb}^{3+}$ ions and four for the $\mathrm{Pr}^{3+}$ ions. These centres can be selectively excited with the adequate laser photon energy, so that the energy levels of each individual centre can be obtained. Polarization spectroscopy reveals a main $\mathrm{C}_{3}$ symmetry for all the centres.

In principle the structure of $\mathrm{LiNbO}_{3}$ permits three possible octahedral locations; $\mathrm{Li}^{+}, \mathrm{Nb}^{5+}$ or a free intrinsic octahedron, all of them having $\mathrm{C}_{3}$ symmetry. By RBS/channeling the occupied site can be determined comparing the angular scans of $\mathrm{Nb}^{5+}$ with those of the dopant ions along relevant directions (channels) [3].

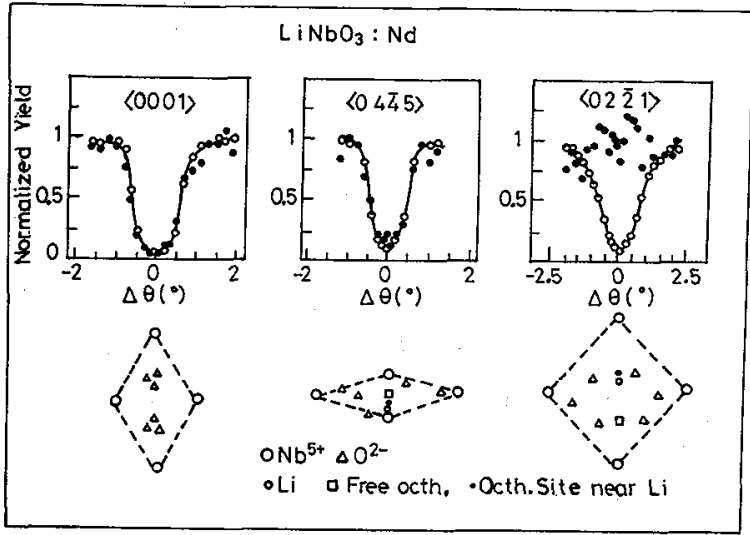

Figure 2 


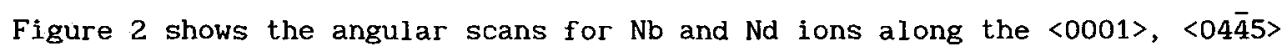
and $\langle 02 \overline{2} 1\rangle$ channels. The projection of the lattice structure on planes perpendicular to these directions have also been displayed. The similar <0001> scans for $\mathrm{Nd}$ (full dots) and $\mathrm{Nb}$ (open dots) indicate that the $\mathrm{Nd}^{3+}$ ions lie, as expected, in the mentioned octahedral positions (all screened by $\mathrm{Nb}$ ions). The scan along the $\langle 04 \overline{4} 5\rangle$ channel excludes the location in the free octahedron, which should produce a flux peak in the Nd yield due to the mid-channel position of these sites. The different $\langle 02 \overline{2} 1\rangle$ angular scans for $\mathrm{Nb}$ and $\mathrm{Nd}$ indicate that $\mathrm{Nd}^{3+}$ ions are located in $\mathrm{Li}$ octahedra. However the anomalous shape of this Nd angular scan suggests that these ions are not located in regular $\mathrm{Li}^{+}$sites. Rather these angular scans have been explained supposing a shifting from the regular $\mathrm{Li}^{+}$site along the $\mathrm{c}$ axis for the dopant ions [3].

The results obtained for $\mathrm{Pr}^{3+}$ ions are similar to those for $\mathrm{Nd}^{3+}$,

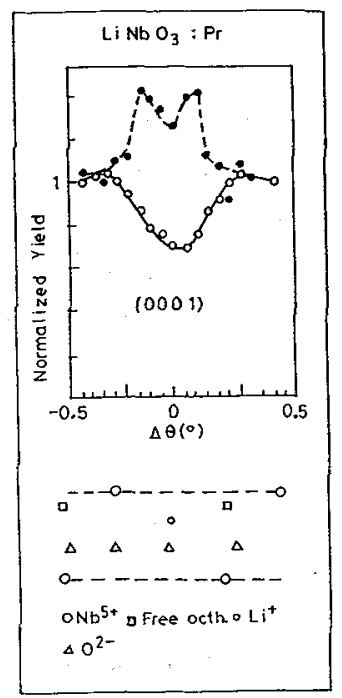

Figure 3 except in the shape of the $\langle 02 \overline{2} 1\rangle$ angular scan which is slightly different for the two ions. As a representative result about this system, figure 3 shows the $\mathrm{Pr}$ and $\mathrm{Nb}$ angular scans along the (0001) planar direction. This channel is particularly adequate to observe how the occupation of the $\mathrm{Li}$ octahedron by $\mathrm{Pr}^{3+}$ ions produce a blocking effect in the channel, giving place to a flux but structured peak. This fact again indicates non regular $\mathrm{Li}^{+}$substituted sites.

RBS/channeling experiments on $\mathrm{LiNbO}_{3}: \mathrm{Yb}$ are being carried out at the present time. First result point out to similar occupation as the previous two cases.

\section{DISCUSSION}

The spectroscopic results indicate the presence of three non-equivalent (or more) sites for the investigated dopant ions. In all of them the dopant ions are in $\mathrm{C}_{3}$ local symmetry and (for $\mathrm{Nd}$ and $\mathrm{Pr}$ ) only the Li-octahedrons are occupied. However the angular scans along some specific channels reveal non regular $\mathrm{Li}^{+}$sites. Thus the non equivalent centres of the dopant ions can be explained as a result of different off-centred positions in the Li octahedron. Figure 4 shows the dependence of the $\left|B_{2}^{0}\right|$ trigonal crystal field parameter as a function of the displacement from the regular $\mathrm{Li}^{+}$position, 
calculated as in ref. [4]. Positive, $x>0$, shifting leads to a more cubic

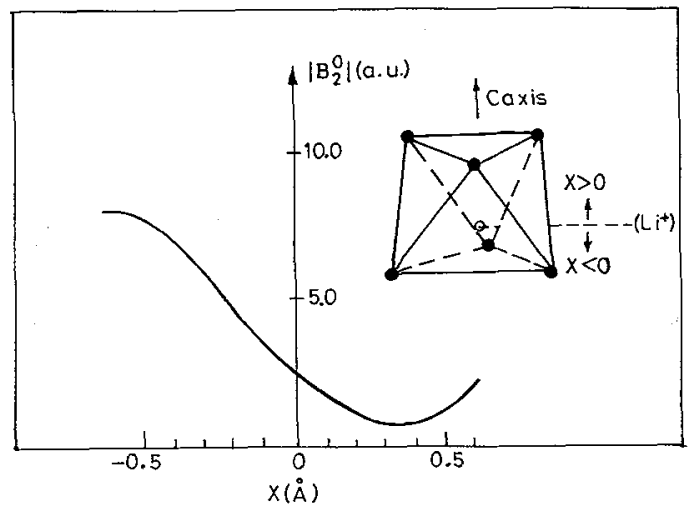

Figure 4

octahedral environment whereas negative, $x<0$, shifting produces a less cubic octahedral symmetry (higher trigonal crystalline field). Therefore the non equivalent multicentres for a determined ion are a consequence of different off-centres positions of the ion in the Li octahedron. The reason for these different off-centre positions has to be related to presence of defects associated to the non-stoichiometry of LiNbO; $\mathrm{Nb}$ antisites, $\mathrm{Nb}^{*}\left(\mathrm{Nb}^{5+}\right.$ ions in $\mathrm{Li}^{+}$sites) and $\mathrm{Nb}$ vacancies, $\mathrm{Nb}$, [5]. In fact the formation of $\mathrm{Nb}^{*}-\mathrm{Nb}_{\mathrm{v}}$ complexes has been reported to be more energetically favorable than the diluted $\mathrm{Nb}^{*}$ and $\mathrm{Nb}$ defects [6]. Thus the formation of the non equivalent $\mathrm{M}^{3+}(\mathrm{Li})-\mathrm{Nb}_{\mathrm{v}}$ and $\mathrm{M}^{3+}(\mathrm{Li})$ complexes, $\mathrm{M}^{3+}$ being the dopant ion $(\mathrm{M}=\mathrm{Nd}$, Pr or $\mathrm{Yb}$ ), could give place to the different $\mathrm{M}^{3+}$ multicentres. However, at the present time, a definite structure for these centres can not be given.

\section{ACKNOWLEDGEMENTS}

One of us, J. García Solé, wishes to acknowledge the Région Rhone-Alpes (France) and Ministerio de Educación y Ciencia (Spain) for financial support.

\section{REFERENCES}

[1] E. Lallier, Appl. Optics, 31, 5276 (1992).

[2] J. García Solé, B. Macalik, L.E. Bausá, F. Cussó, E. Camarillo, A. Lorenzo, L. Nuñez, F. Jaque, A. Monteil, G. Boulon, J.E. Muñoz Santiuste and I. Vergara, J. Electrochem. Soc., 140, No. 7, 2010 (1993).

[3] L. Rebouta, P.J.M. Smulders, D.O. Boerma, F. Agulló-Lopez, M.F. da Silva and J.C. Soares, Phys. Rev.B, 48, No.6, 3600 (1993).

[4] M. Faucher and P. Caro, J. Chem. Phys., 63, No. 1, 446 (1975).

[5] S. C. Abrahams and P. Marsh. Acta Cryst., B 12, 61 (1986).

[6] H. J. Donnerberg, S.M. Tomlinson and C.R.A. Catlow, J. Phys. Chem. Solids, 52, 201 (1991). 